\title{
REDUCING SECLUSION USE FOR TĀNGATA WHAI I TE ORA THROUGH INTEGRATION OF MĀORI CULTURE INTO PRACTICE
}

\author{
Natasha Moore
}

\section{INTRODUCTION}

The definition of seclusion under the Mental Health (Compulsory Assessment and Treatment) Act 1992 (as cited in Ministry of Health $[\mathrm{MoH}], 20 \mathrm{l0}$ ) is "where a consumer is placed alone in a room or area, at any time and for any duration, from which they cannot freely exit" ( $\mathrm{MoH}, 2010, \mathrm{p}$. 7). Seclusion is meant only to be used as a last resort for patients, or proposed patients, admitted to New Zealand mental health services under the Mental Health (Compulsory Assessment and Treatment) Act 1992 (as cited in MoH, 2010). Seclusion can be likened to being stranded alone on an island, disconnected from resources and any potential help. Studies have shown little or no therapeutic value in the use of seclusion, and it has been proven to both negatively influence welfare and disrupt the therapeutic relationship between consumers and healthcare staff (Mellow et al. as cited in Jury et al., 2019; Whitecross, Seeary \& Lee, 2013). The purpose of this literature review is to explore the benefits of integrating Māori cultural practices into nursing practice in an acute inpatient setting, and the potential impact this could have on reducing inequities between Māori and non-Māori in regard to the use of seclusion.

\section{ISSUE}

In March of 2018, with the help of Te Pou o te Whakaaro Nui, the Health Quality and Safety Commission (HQSCNZ) initiated a plan for 'Zero Seclusion' by 2020 (HQSCNZ, 20 I8a). However, recently released statistics show the use of seclusion in mental health practice has been on a steady incline since 2017 (Cooke, 202I). A study completed by McLeod, King, Stanley, Lacey and Cunningham (2017) identified that Māori patients admitted to inpatient mental health units had a rate of seclusion 39 per cent higher than non-Māori patients.

While the end goal is to completely remove seclusion as a practice in New Zealand mental health services (HQSCNZ, 20I8a), in the interim there needs to be significant progress made in reducing the inequities between Māori and non-Māori regarding seclusion statistics (Cooke, 202I; HQSCNZ, 20l8b). A study by Sambrano and Cox (2013) explored indigenous Australians' experiences of seclusion and noted that seclusion served as a continuation of the power imbalance between health service providers and indigenous consumers that has been present since colonisation (Sambrano \& Cox, 2013). These sentiments can also be applied to Māori, the indigenous population of New Zealand. This study indicates seclusion is much more damaging for indigenous people, as it is a continuation of treatment they already expect from healthcare professionals.

Initially, the research question was focused on what could be done to reduce the use of seclusion for Māori patients. However, this is a large topic and much of what is being done to reduce seclusion applies to those of all ethnicities, not Māori specifically. Therefore, the focus became looking at whether integration of Māori culture and practice into mental health care could reduce the use of seclusion for adult Māori patients in acute inpatient mental health care. 


\section{DISCUSSION}

Wharewera-Mika et al. (2016) identified that Māori patients felt that they would benefit from access to a Māori world view. They discussed that freedom for tāngata whai $i$ te ora to access cultural practices and procedures was integral to reducing seclusion and restraint practices. Te Pou o te Whakaaro Nui (2014) and Wharewera-Mika et al. (2016) both discuss the importance of kanohi kitea or kanohi ki te kanohi, meaning 'to be seen' or 'face-toface'. The presence of Māori staff members in a face-to-face environment can be reassuring to Māori patients due to the nature of the connection among Māori to a shared cultural heritage (Te Pou o te Whakaaro Nui, 20I4). Te Pou o te Whakaaro Nui (2014) also suggests this connection can lead to stronger therapeutic relationships between staff and patients, therefore reducing the need for seclusion and restraint due to increased effectiveness of de-escalation techniques. Wharewera-Mika et al. (2016) also discusses kanohi ki te kanohi care in the context of approaching newly admitted Māori patients. By following protocols of sitting face to face with a person, offering food or drink, and using cultural healing practices, such as song or prayer, can restore the mana of the Māori patient (Wharewera-Mika et al., 2016). Following protocols also serves to prevent tension between staff and patients and provides a basis for building working relationships with tāngata whai i te ora. Te Pou o te Whakaaro Nui (2014) explains the pre-entry and admission process into inpatient mental health care can be influential on the entire experience of the patient's mental health journey. Showing hospitality and respecting Māori protocols upon the first interaction with a patient can help form rapport and a therapeutic relationship that can benefit the patient in the long run, as well as reduce agitation and anxiety in the short term, reducing the likelihood for seclusion.

Similarly, it is important for staff, both Māori and non-Māori, to recognise the importance of incorporating Te Reo into their practice. Plessas, McCormack and Kafantaris (2019) identify the use of Te Reo within mental health practice as a recognition of identity as well as a show of respect. Te Pou o te Whakaaro Nui (20/4) also discusses the use of Te Reo in engaging and connecting with tanngata whai i te ora to aid in building stronger therapeutic relationships. They identify the use of Te Reo Māori as necessary in conveying ideas and understanding of a situation that other languages cannot. It is also valuable in engaging tāngata whai ora in conversation with staff. Wharewera-Mika et al. (2019) also explains use of Te Reo in waiata, karakia, or kapa haka can also be useful in culturally appropriate sensory modulation and as a healing practice for Māori patients. Use of Te Reo is also conducive in establishing a strong sense of cultural identity. Wharewera-Mika et al. (2019) identify Māorispecific sensory modulation as beneficial when offering alternative strategies to more restrictive interventions, like seclusion.

Te Pou o te Whakaaro Nui (2014), Wharewera-Mika et al. (2016), Plessas et al. (2019) and Wharewera-Mika et al. (2019) all suggest that by integrating Māori culture and practices into mental health care practice, use of seclusion could be reduced through formation of stronger therapeutic relationships, and use of culturally specific de-escalation and sensory modulation techniques. However, it is important to recognise complexities of cultural identity. As Plessas et al. (2019) point out, some Māori may not hold traditional values, or see Māori cultural practices as relevant or appropriate regarding their care. As with all nursing care, it must be based on the individual's preferences which can be ascertained through thorough communication with the Māori patient (Plessas et al., 2019).

Another barrier in the path to reducing seclusion practices is the accessibility of Māori healthcare staff. Both Wharewera-Mika et al. (2016) and Te Pou o te Whakaaro Nui (2014) identify the importance of Māori healthcare staff in providing a culturally safe environment for patients who identify as Māori, as well as building therapeutic relationships that lead to a reduction in use of seclusion. However, employment of Māori healthcare staff into mental health relies on availability of these staff for employment. Māori make up an estimated 16.7 per cent of the New Zealand population in total as of June 2020 (Statistics New Zealand, 2020), but only 8.5 per cent of the total healthcare workforce identifies as Māori and only 9 per cent of district health boards' mental health and addictions employees are Māori (Te Rau Matatini, 2017). The Māori nursing workforce is even smaller, with only 7 per cent of nurses identifying as Māori (New Zealand Nurses Organisation, n.d.). This is particularly an issue in mental 
health as Māori are more likely, of all ethnicities, to be seen by mental health and addiction services $(\mathrm{MoH}, 202 \mathrm{I})$, making the disparity between the number of Māori staff when compared to the percentage of Māori patients only more apparent. While there are programmes in place to support and encourage more Māori to enter healthcare as a profession, for example: the University of Otago's Māori Health Workforce Development Unit (University of Otago, n.d.), there are still disparities in the number of Māori entering the healthcare profession. This, therefore, impacts on the benefits of having Māori staff as outlined above due to lower numbers of Māori staff in employment, and hinders any progress to be made in reducing seclusion rates of Māori patients. While there are still barriers to change being made, it is evident from the literature above that there are still many options and ways that care could be improved for Māori in an acute inpatient setting in order to reduce the inequities in seclusion statistics.

\section{RECOMMENDATIONS}

\section{Integration of Māori culture and practices into mental health care}

Wharewera-Mika et al. (2016) and Te Pou o te Whakaaro Nui (2014) both suggest that to reduce seclusion rates for Māori, there needs to be changes made to mental health practice at all levels to integrate Māori culture and practices into care, as discussed above. This can include having a Māori staff member, cultural advisor, or kaumatua present, as advised by Te Pou o te Whakaaro Nui (2014), or involve offering the patient food or drink, alongside use of cultural healing practices, such as waiata or karakia (Wharewera-Mika et al., 2016). By welcoming Māori patients onto the ward in a way that respects them and their culture, it can have a positive impact on their own view of the environment and can provide a sense of calm and safety that is integral in reducing the anxiety and agitation, or tension, they might feel otherwise. This reduces the likelihood of the use of seclusion being a necessary factor in the admission process and builds the basis for a strong therapeutic relationship with the patient that will not only benefit their health outcomes, but also improve the chances of having no further use of seclusion while on the ward (Te Pou o te Whakaaro Nui, 2014; Wharewera-Mika et al., 2016).

\section{Involve Māori staff in the care of Māori patients}

Wharewera-Mika et al. (2016) and Te Pou o te Whakaaro Nui (2014) both conclude that having Māori staff, including Māori nurses, involved in the care of Māori patients can reduce the use of seclusion on these patients, as well as improve overall health outcomes. This includes having Māori health practitioners involved in all levels of care, as well as the input of Māori mental health assistants and Māori cultural advisors. It is expected that the use of seclusion will reduce due to the stronger therapeutic relationship built between Māori staff and tāngata whai i te ora, with Māori staff better equipped to de-escalate the patient due to the shared relationship. However, this recommendation relies on the availability for Māori staff, therefore, it is also implied that inpatient mental health providers should put emphasis on employing and retaining Māori staff members as they are invaluable in potential to reduce Māori seclusion rates. It is also advised for facilities to have input of cultural advisors, including kaumātua and kuia, to provide guidance and education for both staff and patients and to promote culturally specific interventions in place of seclusion use (Te Pou o te Whakaaro Nui, 20I4; Wharewera-Mika et al., 2016).

\section{Improve staff knowledge of Māori practices/culture}

In order to achieve the goal of integrating Māori culture into practice, it is important that the staff knowledge base of Māori culture and practices improves, and staff recognise the benefits of integrating this into their care. While it is required for both registered nurses and enrolled nurses to provide culturally safe care and apply the principles of Te Tiriti O Waitangi to nursing practice (Nursing Council of New Zealand [NCNZ], 2007; NCNZ, 2012), it is oftentimes up to the nurse's own personal judgement on whether they meet this requirement. Te Pou 
o te Whakaaro Nui (2014) suggests it would be appropriate to allow opportunities for experienced Māori mental health professionals to provide cultural and practical advice to non-Māori staff, including nurses. The findings of Wharewera-Mika et al. (2016) saw value in developing and facilitating Māori peer support initiatives. More general education provided to staff of common Te Reo phrases or Māori practices could also slowly build up the knowledge base of staff and increase their confidence in day-to-day use of this knowledge in practice. This could be achieved in ways as simple as having an accessible list of common Māori phrases available to staff. Cultural advisors could also play a role in education of staff through in-service training. By having non-Māori staff engaging with Māori culture and practice when providing care, it can create an environment that is less hostile and more inclusive of tāngata whai $i$ te ora, and therefore reduce seclusion use and improve health outcomes (Te Pou o te Whakaaro Nui, 2014; Wharewera-Mika et al., 2016).

\section{CONCLUSION}

In summary, seclusion is not a useful practice in mental health care as it is essentially leaving consumers stranded alone on an empty island. Seclusion use is particularly damaging to tāngata whai i te ora. This is because seclusion is a continuation of the degrading and discriminatory treatment Māori have been facing since colonisation. Maori also have much higher rates of seclusion than any other ethnicity in New Zealand. According to the literature, reducing seclusion for tāngata whai ora can be achieved by integration of Māori culture and practices, such as use of Te Reo, culturally specific de-escalation techniques, and Māori protocols into mental health care, and the involvement of Māori staff members the care of Māori consumers, at all levels. Therefore, it is necessary to implement changes in practice to accommodate integration of Māori culture and practices to reduce seclusion use. This can be done through a stronger focus on building the therapeutic relationships integral in care starting at admission, employing more Māori staff to meet the needs of Māori patients, and educating staff on Māori culture and practices. The ideal outcome being to reduce or eliminate seclusion use, or other restrictive practices, in inpatient mental health care for tāngata whai i te ora.

Natasha Moore is a third-year nursing student completing her Bachelor of Nursing with Otago Polytechnic. Her interest in seclusion reduction and equity in mental health care developed throughout her experiences on placement during her studies. She hopes to apply this to her future practice.

Correspondence to: Natasha Moore. Email: natasha.moore307@gmail.com 


\section{REFERENCES}

Cooke, H. (2021). Huge growth in use of 'last resort' seclusion indicates mental health system in crisis, and in worse shape than when Labour elected in 2017. Stuff News. Retrieved from https://www.stuff.co.nz/national/politics/300266892/hugegrowth-in-use-of-last-resort-seclusion-indicates-mental-health-system-in-crisis-and-in-worse-shape-than-when-labourelected-in-2017

Health Quality \& Safety Commission New Zealand. (2018a). New projects seek to eliminate seclusion and improve service transitions for mental health consumers. Retrieved from https://www.hqsc.govt.nz/our-programmes/mental-health-and-addictionquality-improvement/news-and-events/news/3162/

Health Quality \& Safety Commission New Zealand. (2018b). Zero seclusion: Towards eliminating seclusion by 2020 [Infographic]. Retrieved from https://www.hqsc. govt.nz/assets/Mental-Health-Addiction/Resources/Zero_seclusion_infographic_ Mar_2018.pdf

Jury, A., Lai, J., Tuason, C., Koning, A., Smith, M., Boyd, L., Swnason, C., Fergusson, D., \& Gruar, A. (2019). People who experience seclusion in adult mental health inpatient services: An examination of health of the nation outcome scales scores. International Journal of Mental Health Nursing, 28(1), 199-208. doi:10.1 I I/inm. 12521

McLeod, M., King, P., Stanley, J., Lacey, C., \& Cunningham, R. (2017). Ethnic disparities in the use of seclusion for adult psychiatric inpatients in New Zealand. New Zealand Medical Journal, I30(1454), 30-39. Retrieved from https://journal.nzma.org.nz/ journal-articles/ethnic-disparities-in-the-use-of-seclusion-for-adult-psychiatric-inpatients-in-new-zealand

Ministry of Health. (202I). Mental health and addictions: Service use 2017/I8 tables. Retrieved from https://www.health.govt.nz/ publication/mental-health-and-addiction-service-use-2017-18-tables

Ministry of Health. (2010). Seclusion under the mental health (Compulsory Assessment and Treatment) Act 1992. Retrieved from https://www.health.govt.nz/system/files/ documents/publications/seclusion-guidelines-febl0.pdf

New Zealand Nurses Organisation. (n.d.). NZNO strategy for nursing 2018-2023. Retrieved from https://www.nurses.org.nz/ nursing_workforce

Nursing Council of New Zealand. (2007). Competencies for registered nurses. Retrieved from https://www.nursingcouncil.org.nz/ Public/Nursing/Standards_and_guidelines/NCNZ/nursing-section/Standards_and_guidelines_for_nurses.aspx

Nursing Council of New Zealand. (20I2). Competencies for enrolled nurses. Retrieved from https://www.nursingcouncil.org.nz/ Public/Nursing/Standards_and_guidelines/NCNZ/nursing-section/Standards_and_guidelines_for_nurses.aspx

Plessas, A., McCormack, J. \& Kafantaris, I. (2019). The potential role of applied behaviour analysis in the cultural environment of Māori mental health. Behaviour Analysis in Practice, 12(4), 854-868. doi:10.1007/s40617-019-00359-0

Sambrano, R. \& Cox, L. (2013). 'I sang Amazing Grace for about 3 hours that day': Understanding indigenous Australians' experience of seclusion. International Journal of Mental Health Nursing, 22(6), 522--531. doi:10.1 I I I/inm. 12015

Statistics New Zealand. (2020). Māori population estimates: At 30 June 2020. Retrieved from stats.govt.nz/information-releases/ maori-population-estimates-at-30-june-2020

Te Rau Matatini. (2017). Profiling the Māori health workforce 2017. Retrieved from https://terauora.com/wp-content/ uploads/2019/05/Profiling-of-the-Ma\%CC\%84ori-Health-Workforce-2017_Te-Rau-Matatini.pdf

Te Pou o Te Whakaaro Nui. (2014). Supporting seclusion reduction for Māori: "Taiheretia tatou kia puta te hua". Retrieved from https://www.tepou.co.nz/resources/supporting-seclusion-reduction-for-māori

University of Otago. (n.d.). Māori health workforce development unit. Retrieved from https://www.otago.ac.nz/mhwdu/index.html

Wharewera-Mika, J., Cooper, E., Wiki, N., Field, T., Haitana, J., Toko, M., Edwards, E., \& McKenna, B. (2016). Strategies to reduce the use of seclusion with tāngata whai i te ora (Māori mental health services users). International Journal of Mental Health Nursing, 25(I), 258-265. doi:10.11 II/inm. 12219

Whitecross, F., Seeary, A. \& Lee, S. (2013). Measuring the impacts of seclusion on psychiatry inpatients and the effectiveness of a pilot single-session post-seclusion counselling intervention. International Journal of Mental Health Nursing, 22(6), 512-52I. doi:10.1 III/inm. 12023 